\title{
THE 'WAY OF FLOWERS' AND THE CARE OF PATIENTS WITH AMYOTROPHIC LATERAL SCLEROSIS IN JAPAN
}

\author{
YUKIKO HIMENO \\ Assistant Professor, Ritsumeikan University \\ hime@fc.ritsumei.ac.jp
}

OsAmu INOUE Associate Professor, Kyoto University of the Arts; Academic Counselor, Headquarters of Kadō, Old Saga Imperial Palace o-inoue@kua.kyoto-art.ac.jp

Fernando Vidal Research Professor, Catalan Institution for Research and Advanced Studies (ICREA); Professor, Medical Anthropology Research Center-DAFITS, Rovira i Virgili University fernando.vidal@icrea.cat

ABSTRACT: Tracheostomy with invasive ventilation (TIV) may be required for the survival of patients at advanced stages of amyotrophic lateral sclerosis (ALS). In Japan it has been shown that a proactive approach toward TIV may prolong the survival of ALS patients by over 10 years by preventing the lethal respiratory failure that generally occurs within 3-5 years of the onset of the disease. Measures to prolong life expectancy without foregoing quality of life have produced better results in Japan than in other developed countries. This 'Japanese bias' has been attributed to socio-cultural and religious factors as well as to the availability of material resources in Japan. In this article, we use the concepts of onozukara in kado (Japanese traditional flower art, also called ikebana) and amae (passive love) to illuminate features of patient care that may contribute to this 'Japanese bias'. 
KEYWORDS: amyotrophic lateral sclerosis (ALS); tracheostomy with invasive ventilation (TIV); kadō (ikebana); locked-in syndrome (LIS); philosophy of basho

RESUMEN: La ventilación mecánica invasiva por traqueotomía (VMI) puede ser necesaria para la supervivencia de personas en la etapa avanzada de la esclerosis lateral amiotrófica (ELA). Se ha demostrado que un enfoque proactivo hacia la VMI en Japón posiblemente prolongue la supervivencia de los pacientes con ELA por más de 10 años al evitar la insuficiencia respiratoria letal que generalmente ocurre dentro de los 3 a 5 años del inicio de la enfermedad. En comparación con otros países desarrollados, Japón obtiene buenos resultados por lo que se refiere a prolongar la esperanza de vida sin sacrificar la calidad de vida. Este «sesgo japonés» (Japanese bias), como se lo ha llamado, se ha atribuido a factores socioculturales y religiosos, así como a los recursos materiales disponibles en el Japón. En este artículo, utilizamos los conceptos de onozukara en kadō (arte floral tradicional japonés, también llamado ikebana) y de amae (amor pasivo) para iluminar las características de la atención al paciente que podrían contribuir a producir el «sesgo japonés».

Palabras clave: esclerosis lateral amiotrófica (ELA); traqueotomía con ventilación invasiva (TIV); kadō (ikebana); síndrome de cautiverio (LIS); filosofía del basho 


\section{Introduction}

Amyotrophic lateral sclerosis (ALS) is a disease in which patients lose their ability to move due to the degeneration of motoneurons. The degeneration of respiratory neurons leads to hypoventilation and causes death within 3-5 years if breathing support is not provided. This support requires artificial ventilators, of which there are two types. One is tracheostomy with invasive ventilation (TIV) and the other is non-invasive ventilation using a nasal mask (NIV). TIV leads to better prognosis than NIV (Dreyer et alii, 2014; Hirose et alii, 2018; Kimura, 2016; Tagami et alii, 2014). So far, however, it has been impossible to cure the disease or to stop its progress. Prolonging life expectancy using TIV therefore entails a strong probability that patients will enter the locked-in state, which is characterized by complete immobility and a loss of verbal communication abilities while fully conscious. A Polish observational study found that most patients are satisfied with their decision to choose TIV and percutaneous endoscopic gastrostomy for nutrition. Such patients also report a reasonable quality of life (QOL), low levels of depressed mood, and a commitment to living (Kuzma-Kozakiewicz et alii, 2019). However, larger studies of living with ALS and TIV in a locked-in state are needed to determine how generalizable this result may be (Albert and Wicks, 2019).

A study of QOL in patients with ALS and locked-in syndrome (LIS) showed that the difference in QOL between a group with TIV and one with NIV was not significant (Rousseau et alii, 2011). However, guidelines for the therapeutic care of ALS suggested by the American Academy of Neurology and the European Federation of Neurological Societies emphasize the potential economic, social, and mental burdens of TIV and suggest that patients should adopt a cautious approach toward tracheostomy (Miller et alii, 1999, 2009; Andersen et alii, 2005, 2012). While they note that TIV may be effective in preserving QOL for patients with ALS with respiratory insufficiency, it also involves a risk that patients will enter LIS and likely generates a greater burden for caregivers. Such guidelines can incite fear in patients and families and encourage them to reject TIV in favor of NIV. 
In Japan, there are roughly 10,000 patients with ALS while between 1,000 and 2,000 new patients are diagnosed each year. Some hospitals began recommending home use of TIV in the 1970s. Thanks to information exchange, mutual encouragement among ALS patient networks, and economic and social support at the state level, the rate of TIV users reached an average of $30 \%$, ranging from $25 \%$ to $46 \%$ (Rabkin et alii, 2014). This is much higher than the rates in the UK (0\%), Canada (1.5\%), France (2-5\%), Germany (3\%) and the US (1.4-14\%). The difference with respect to the US appears to be caused by starkly unequal access to the extremely high medical expenses involved in ALS care. TIV acceptance rates in Asian countries (12.7-21\%) are generally higher than in Western European countries. Also, although Denmark (22\%), Italy (30\%) and Spain (33\%) present comparatively high rates, the prognosis after TIV in those countries is poor compared with Japan (Chiò et alii, 2010; Dreyer et alii, 2014; Sancho et alii, 2011; Spataro et alii, 2012; Tagami et alii, 2014). The greater acceptance of TIV in Japan, combined with a better survival prognosis, has raised questions about the role that religious, ethnic, social and cultural factors may play in creating such differences.

In an editorial published in the Journal of the Neurological Sciences, Andrea Vianello and Alessandra Concas, from the Respiratory Pathophysiology Division at the University-City Hospital of Padova in Italy, speak of a 'Japanese bias' and wonder whether this bias will be eliminated by globalization (Vianello and Concas, 2014). Numerous factors interact dynamically to encourage ALS patients to decide in favor of TIV and successful long-term care. Certainly, the level of financial support and the structure of social systems and services for ALS are crucial (Kawaguchi, 2020). Considerable resources are needed to care for paralyzed patients and help them to achieve a good QOL. Material resources, however, are probably not enough to explain the 'Japanese bias'. On the one hand, many developed countries present lower rates of TIV use by patients with ALS despite comparable medical systems and similar economic power to the Japanese. On the other hand, in countries where the rate of TIV acceptance is as high as in Japan, life expectancy for those patients is lower. A clue to understanding this may be found in the 
cultural background of care. Of course, this does not help to explain why so many people who are affected with ALS (ca. 70\%) choose not to go on TIV. Rather than 'explain' or reveal causal factors, however, our goal here is to highlight a certain consistency between the dynamics of care and several cultural features particular to Japan.

Kawaguchi Yumiko (2020)1, former president of the Japanese ALS Association (JALSA), discussed changes in the attitudes of family members after they receive information about the care services available to them and argued that patients' close relatives play an important role in encouraging them to choose TIV. In the last two decades, patients with ALS in Japan have fought for better social support, obtaining conditions that enable them to continue living without depending mainly on their families. This system includes caregivers who are often trained by JALSA members. Formerly, family members acting as caregivers were the key players in prolonging life expectancy in ALS patients with TIV. Nowadays, however, that role has been taken on by experienced, specialized professional caregivers.

After interviewing one of these caregivers, philosopher Murakami Yasuhiko described a typical temporal structure characterized by the intensive care of an ALS patient with a ventilator and extremely slow communication. The sustained continuity of care gives rise to an intersubjective history, which in turn becomes the condition and context for the caregiver's capacity to fill in the gaps in communicative signals. This capacity is existentially crucial since failures in communication increase the risk of a fatal accident for the patient (Murakami, 2020). Murakami's study, together with Kawaguchi's memoir of caring for her mother, who suffered from ALS and entered the locked-in state (Kawaguchi, 2009), inspired us to explore the possible link between the 'Japanese bias' and certain philosophical concepts developed in Japan. We hypothesize that such a link is not of a causal nature but takes the form of a certain attitude toward giving and receiving care, a certain consistency between what the explored concepts may imply, and the cognitive, emotional and behavioral dimensions of patient care. We shall proceed in three steps.

1 Japanese names are given here in the Japanese way, i.e. with the family name preceding the given one. 
First, we introduce the concept of basho (place) developed by Nishida Kitarō (1870-1945), a cofounder and central figure of the Kyoto School of Philosophy, especially in connection with intersubjectivity. Second, we refer to geido (usually translated as 'the way of art' or 'the way of the arts', and sometimes as the 'art-way') to examine how a philosophical idea materializes as practice, with a focus on onozukara. Onozukara is a crucial concept in both geidō and Shintō (a religion indigenous to Japan) and signifies that an act is performed naturally. Onozukara is regarded as an ideal state in the different 'ways' that geidō encompasses. Here we shall concentrate on kadō, the 'way of flowers', and explore affinities with care in the way it deals with life. Finally, we refer to the concept of amae, developed by Japanese psychiatrist Doi Takeo (1920-2009), to interpret the relationship between an ALS patient and their caregiver. Amae is usually translated as 'dependence' or even 'spoiled', though sometimes it is also as translated as 'need-love', 'indulgent dependency' or 'desire to be indulged', which evokes nurturance needs but lacks the negative connotations of the English terms. Amae has a kinship with onozukara in that both terms denote processes that blur the distinction between self and world, subject and object. ${ }^{2}$ As we shall see, subverting this distinction is a major element of basho. Here we use these concepts to explore dimensions of the phenomenology of patient care that may contribute to shaping Japanese practices and therefore give rise to the 'Japanese bias'. We therefore seek to advance intercultural phenomenological comparisons and the descriptive and interpretive potential of concepts that are unfamiliar to medical anthropology and phenomenology as practiced in most academic environments. Drawing inspiration from Chikako Ozawa-de Silva (2002), we shall not take these concepts as ethnographic objects but seek to imagine the work they could perform to explain the dynamics of patient care in ways that may apply to Japan and beyond. It should be clear that we do not consider that these concepts

2 For a succinct discussion of the linguistic difficulties involved in philosophical translation, see Raud (2014). This author observes, for example, that the tendency of Western philosophy "to allocate to tangible objects a higher degree of existence than to phenomena in flux" does not fit very well with the structure of the Japanese language (Raud, 2014:21). In turn, this structure partly accounts for the challenges of rendering Japanese thought in Western languages. 
encapsulate 'Japanese thought' or 'Japanese culture' as wholes (Kopf, 2003). Moreover, we endeavor to avoid both the stereotypes that have long placed East and West in opposing or complementary relationships (Clarke, 1997) and beliefs about Japanese exceptionalism that are often associated with nihonjinron, a body of academic and popular discourse that claims to demonstrate Japan's cultural identity (Sugimoto, 1999).

\section{Basho, kadō and amae}

During the Meiji period (1868-1912), Japan ceased to be a feudal society and emerged as a modern, industrialized nation-state (Jansen, 2000). Western influence at the time involved not only commerce, science, technology and politics but also academic disciplines, practices and conceptual realms - including art, philosophy, medicine and aesthetics. The assimilation and integration of concepts and traditions of thought were difficult and full of tensions. A major figure in that process was Nishida Kitarō (Davis, 2010; section on the Kyoto School in Heisig, Kasulis and Maraldo, 2011; Kasulis, 2018, ch. 12). Of Nishida, John Maraldo (2019) writes that he was

the most significant and influential Japanese philosopher of the twentieth-century. His work is pathbreaking in several respects: it established in Japan the creative discipline of philosophy as practiced in Europe and the Americas; it enriched that discipline by infusing AngloEuropean philosophy with Asian sources of thought; it provided a new basis for philosophical treatments of East Asian Buddhist thought; and it produced novel theories of self and world with rich implications for contemporary philosophizing.

One of Nishida's goals was to position and explain Japanese or East Asian thought within the framework of Western philosophy. Nishida's signature theory of basho, which he developed in the mid-1920s, embodies his attempt to overcome epistemological dualism and ontological substantialism - the dichotomies of subject and object, future and past, self and nature, idealism and realism, and experience and reality - and provides the foundation for a philosophy of experience and self- 
awareness. Basho means 'place'. Choosing to leave the term untranslated, Thomas P. Kasulis (2018: 463) explains that it can be used "in the sense of where or how an experience or a judgment in experience takes place," but that it also "topicalizes an experience by establishing a standpoint or engulfing context for the way something is judged and it localizes every judgment in terms of its larger experiential context." He quotes from Nishida: "It is not that there being the individual, there is experience; but instead that there being experience, there is the individual" (Kasulis, 2018: 457).

In his introduction to Nishida's seminal essay "Basho," of 1926, John W. M. Krummel (2012:3-4) elaborates:

Basho in its deepest sense is understood as the concrete situation, i.e. the 'placedness' or 'implacement' of our lived experience vis-à-vis reality, in the whole of its dynamic structure, that grounds cognition and whence the bifurcation into subject-object derives. The attraction of Nishida's basho-theory is in providing a philosophical glimpse into that concrete situatedness that we all live and experience 'always already' (immer schon), and from which we thus find ourselves having 'fallen from grace' in thinking about it.

Krummel (2018: 96) further explains that Nishida proposed 'place' as a solution to the issue of the oppositions between terms of ontologically distinct kinds - subject and object, ideal and real, mind and matter, ought and is, validity and existence, and so on - that problematize their relationships. Simply put, he saw place as the lived and living, concrete and dynamic immediacy from out of which such dichotomized terms are abstracted. He took the wholeness of that immediacy, logically preceding the terms, as implacing them and permitting their relationship. The subject-object duality itself then is but an intellectual abstraction, after-the-fact, of that lived holistic immediacy [...] he had called 'pure experience' [...]. But in 1926, he comes to understand this in terms of "place" (basho) as what envelops subject and object finding their place within it. 
It is within this framework that Nishida recognized the importance of embodiment for human interaction and communication. For him the body was "not primarily a physical object and product of the natural world, but a historical subject and co-creator of the world" and each individual entails "a plurality of interrelated individuals" such that the existence of each depends on being recognized as the other (Maraldo, 2019). Nishida's thought on embodiment and interpersonal relatedness and on the co-emergence of embodied self and world have deep affinities with the phenomenological tradition of Western philosophy (Krueger, 2008). The core of these ideas is captured in his notion of the 'non-relative other' or 'absolute otherness'. As Gereon Kopf (1999: 112-113) explains,

Nishida argues that the mutual interplay of I-Thou necessitates a transcendent region inside the self, which the self encounters as nonrelative negation [...]. While the negation by an external other reaffirms the differentiated world of the self-conscious self and, at the same time, completely separates 'the world of the I' and 'the world of the Thou,' the dialectical encounter of I-Thou necessitates an internal negation, which collapses the dichotomization of the world of interaction into immanence and transcendence and, subsequently, transforms the fundamental structure of the self-conscious self. Nishida identifies this transcendent region inside the self, which simultaneously affirms and negates the self, as non-relative other (zettai no ta). The non-relative other functions as affirmation-qua-negation in that it simultaneously destroys and creates the self; to quote Nishida, 'when the non-relative other kills the I, it gives birth to the I.

Nishida was not alone in considering self and other in 'relational' terms. Thus, following Martin Heidegger's notion of Mitsein (beingwith), Watsuji Tetsurō (1889-1960) developed the notion of aidagara ('in-between-ness', 'interpresence', 'intersubjectivity') to describe "the interpersonal dynamic which exists among individuals and which essentially constitutes the fundamental nature of what it means for one to be a 'self'" (Arisaka, 2001, 198). Later, the psychiatrist Kimura Bin (born 1931) traced the origin of schizophrenia to a failure of aida, the in-between space that embodies the unity of the I and the world, the self and the 
other (Phillips, 2001); in his view, which he attributed to the Japanese in general, aida is primordial and is what enables the actualization of self and other.

Watsuji's observation that the Japanese language developed for artistic expression rather than academic discourse (Watsuji, 2016: 22) opens the pathway to the significance of 'art' for approaching the 'Japanese bias' from the point of view of practices. It is not the particular arts that are significant here but geido, 'the way of art'. Developed in the medieval period, geidō is an expression of the artist's pursuit of self-awareness. The philosopher Kurasawa Yukihiro (1987) defined geidō as the reciprocal pathway between shinjin (true mind) and works of art. Nishida himself was a practitioner of one of its forms, i.e. shodō, the way of calligraphy (on geidō in the Kyoto school, and Nishida in particular, see Bouso, 2018). The modern philosophy of geido was developed by one of Nishida's disciples, Hisamatsu Shin'ichi (1889-1980), who was a master of chadō, the way of tea. During a colloquium in May 1958 at the University of Freiburg, in response to Heidegger's question about whether the Japanese have a word for 'art', Hisamatsu explained that the term for the "Western aesthetic concept of art" is a compound including gei, which "originally means art as ability [Können] in general, skillfulness"; and added:

There is another older word for 'art' - an old Japanese word with a deeper sense that is uninfluenced by Europe. This is gei-do: the way of art. Do is the Chinese tao, which not only means way as method but has a deep internal relationship to life, to our nature [Wesen]. Thus, art has a decisive meaning for life itself. (Heidegger, Hisamatsu et alii, 2017:48)

Of all the various 'ways', kadō is particularly significant for our topic. At the heart of kadō lies the analogy between flowers and human beings, which opens the way for turning flowers into a means for self-awareness. The word that captures the essence of this process is onozukara. One of the most influential kadō books, Ikenobō Sen'ō kuden, which was written in the sixteenth century, declared that the aim of kado is not to express the beauty of flowers but to convey onozukara (Ikenobō, 1970: 1). Although, as suggested above, the concept is difficult to translate, looking at how it works in kado highlights its significance as a fundamental principle of 
nature. Onozukara is an adverb and applies to the basho where a human being and a flower are encompassed together. This basho is not a place where things are physically situated but a locus of understanding of self and circumstances - as when Nishida writes that self is not a point but a circle, not an object but a basho (Nishida, 1949: 279).

By using flowers, a symbol of temporality, kado expresses basho as including all dimensions of time, where buds, blooming flowers, and the withered state coexist. Also manifesting atemporality, this is captured in the traditional kado theme of the "lotus in the three worlds", which articulates past, present and future by using lotus buds, flowers or fruits (Figure 1).

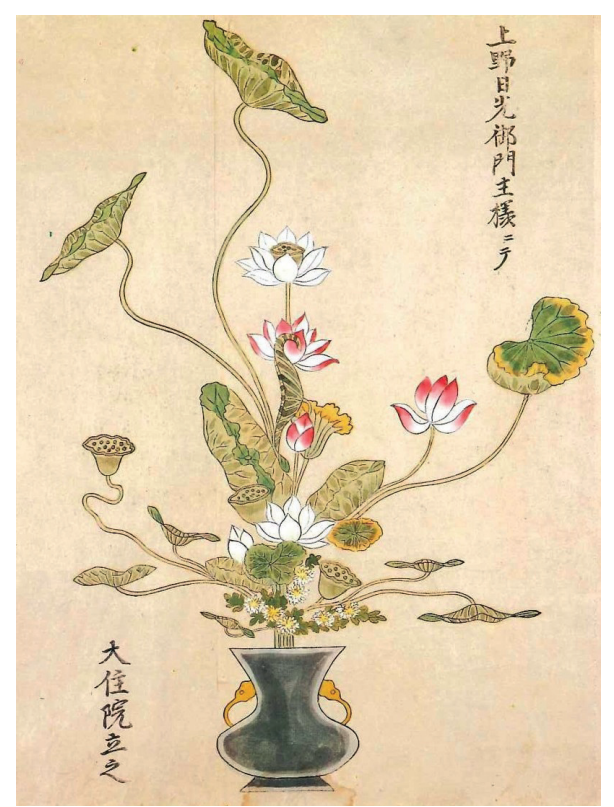

Figure 1. "Lotus in the three worlds", arranged by a priest in the seventeenth century.

Source: Ikebana Bi Ju Zen Shu [Ten Complete Collections of Ikebana Arts], vol. 4.

(Tokyo, Shueisha, 1982).

Atemporality implies that subject and object, persons and world, or I and you become undifferentiated in the basho of kadō. It is instructive that one of the most important schools of traditional kadō is named Mishō, which means 'unborn' or 'undifferentiated'. Kadō encourages practitioners 
to reach self-awareness by contemplating flowers as a symbol of nature, and this state of self-awareness can be adverbially expressed as onozukara. As the eighteenth-century physician and kado master Irie Gyokusen wrote, "feel flowers and know the heart of them"; the state of onozukara does not mean 'to do' something but 'to be' as flowers (Irie, 1970: 12). Or, as Nishida put it, "We become flowers when we see them" (Nishida, 1996: 116) (Figure 2).

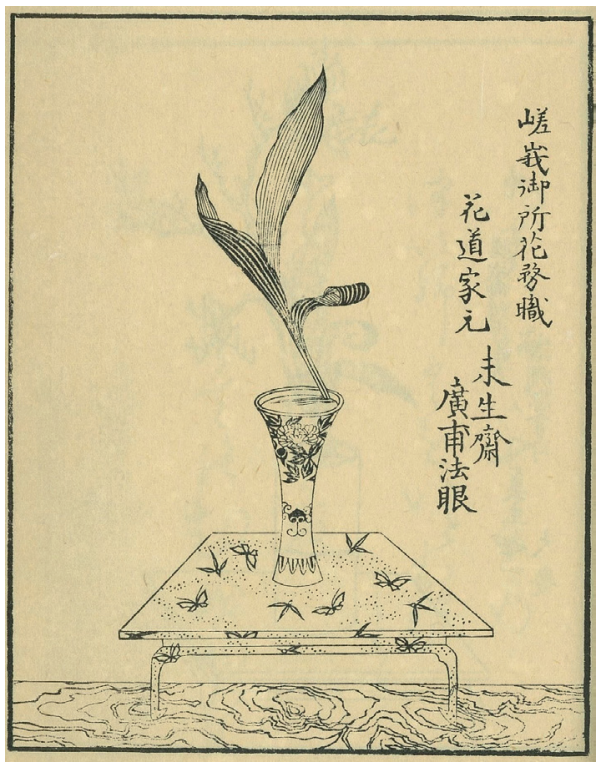

Figure 2. A traditional arrangement by grandmaster of kado Mishosai Koho (1791-1861). Three leaves of aspidistra in the center, right and left represent, respectively, heaven, earth, and human beings, symbolizing the undifferentiation of the universe. Dated 1830.

Source: I. Kumakura and O. Inoue, Cha to Hana [Tea and Flower] (Tokyo: Yamakawa Shuppannsha, 2020).

In his influential The Anatomy of Dependence, the psychoanalyst Doi Takeo (1971) proposed amae (whose translations we discussed above) as a key to Japanese attitudes and behavior. Like Nishida, he sought to break down the dichotomy of objective and subjective. The paradigm here is the relationship between children and their parents. According to Doi, the amae characteristic of Japanese child-rearing practices is not only encouraged in early life but extends into adulthood. In Japan, it is common 
for young children to sleep with their parents, and co-sleeping has remained a remarkably stable practice despite sociodemographic trends that could have undermined it (Shimizu, Park and Greenfield, 2014). In the 1960s, medical anthropologist William Caudill (1969: 41) found that Japanese mothers passively remained in the room with their baby, while American mothers left the child once they finished caretaking. Reporting that Japanese mothers tended to lull their babies to sleep before putting them to bed, while American mothers put them to bed before they fall asleep, he proposed that differences in childcare style at the suckling stage exert a determining influence on the development of personality. According to Doi (1971), the original form of amae appears when the baby wants to adhere tightly to the mother while ambiguously beginning to grasp her as a separate entity. These features of childcare style in infancy, with the continuous presence of the caretaker nearby, likely contribute to amae in individuals brought up by Japanese parents.

This explains why Japanese society is often described as 'maternal' (e.g. Eto, 1978; Nakane, 1970; Kawai, 1997; Ozawa-de Silva, 2006: ch. 5). The intersubjective and ontological configuration captured in the idea of amae conveys the fact that the self is interdependent, breaks down the dichotomy between integration and independence, and emphasizes that individual human existence is inseparable from society or the world. This depiction is more complex than the usual way of differentiating between Western and Japanese views of self and other in terms of 'independent' and 'interdependent' (e.g. Markus and Kitayama, 1991). It also requires approaching illness not as a condition of the affected individual alone but as a social and intersubjective phenomenon embedded in one's relationship to the world and others.

\section{The way of care of ALS patients}

ALS patients gradually lose the ability to move voluntarily. This can lead to patients' adopting TIV and entering the locked-in state. The daughter of an ALS patient in the total locked-in state recounted how she cared for her mother attentively as she grew an orchid (Kawaguchi, 2009). The orchid was a metaphor for the mother and seemed to symbolize 
the fusion between the flower and the caretakers. The latter checked humidity and temperature and calculated liquid balance in order to look after the mother as carefully as if she had been a flower in a greenhouse, thus embodying the above remarks by Irie and Nishida that the state of onozukara means 'to be' as flowers. The daughter and caretakers did not see the patient's body as an object but as a subject, and cared for it onozukara. By reflecting on this situation through the philosophy of kado, we glimpse the agreement between practices of care described in certain patients' testimonies and the practice of geido, as if the concept of 'the way' could be extended into caregiving. We shall now explore this agreement through first-person narratives.

Several clinical reports on decision-making by ALS patients have been published in English-language scientific journals (Christodoulo et alii, 2015; Hirano and Yamazaki, 2010). However, only two are based on firstperson Japanese testimonies (Murakami, 2020; Kawaguchi, 2020). While many narratives, essays, articles and books have been written by patients and caregivers in Japan, these are in Japanese and have not made it into English-language research (Figure 3).

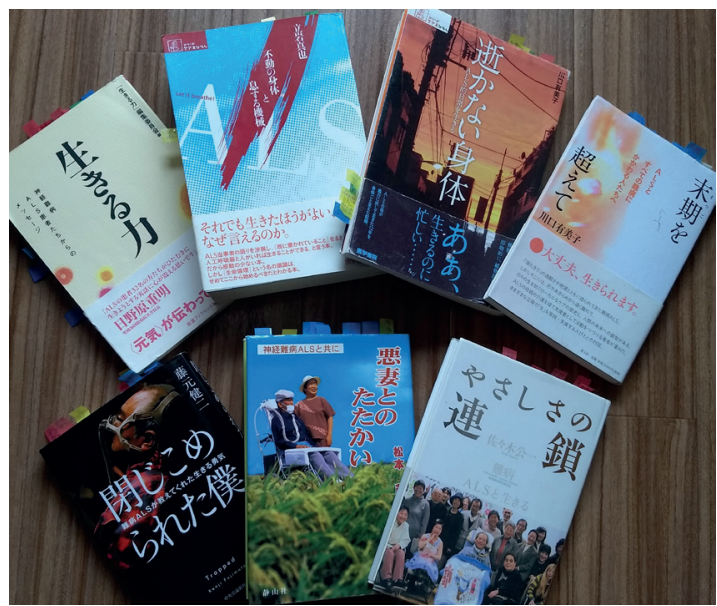

Figure 3. Book covers of ALS patients' narratives. Top, from left to right: Ikiru Chikara

[Power to live] (2007), ALS Fudo no Shintai to Iki Suru Kikai [ALS Immovable Body and Breathing Machine] (2004), Ikanai Shintai [The Body Still Breathing] (2009) and Matsugo wo Koete [Beyond Terminal] (2014). Bottom: Tojikomerareta Boku [Trapped] (2017), Akusai tono

Tatakai [Fight with Bad Wife] (1995) and Yasashisa no Rensa [Chain of Affection] (2006). 
In this section we introduce some of these materials by directly translating the original texts. Here we should also mention a book that was a milestone in ALS studies in Japan. Written by Tateiwa Shin'ya, a sociologist at Ritsumeikan University whose work deals with disability, aging, disease, and diversity, it massively quotes ALS narratives (Tateiwa, 2004).

We begin with a book by Matsumoto Shigeru, former president of JALSA, which he wrote by using a PC switch attached to his chin (initially to his fingers or legs) to input letters one by one. Entitled Akusai to no tatakai (The Fight with a Bad Wife), the book consists of dialogues between the author and his wife. In Japan, it is not uncommon for patients to write tōbyōki, which literally means diary ( $k i)$ of a fight ( $t \bar{o})$ against disease (byō) and is translated as 'illness narratives'. Although the word 'fight' is normally associated with the disease, Matsumoto used it in connection with his wife. The reason for this, he explained, is that misunderstandings between patients and caregivers, derived mainly from the dissymmetry between them, always exist. With the title of his book, Matsumoto was emphasizing that ALS, far from being limited to the patient's own body, is shared with others - in his case, his wife as a caregiver. This implies that the 'place' of ALS care is not limited to the person's body but encompasses the totality of his subjective and intersubjective world, or basho. Indeed, the physical life of ALS patients inevitably depends on others helping them, and this specific condition sheds light on the basho of care. Let us first consider Matsumoto's feelings on deciding to go on TIV.

Matsumoto stated his desire clearly: "I will die if I do not go on tracheostomy. I don't want to die." He then went on to explain: "People say, 'there is no need to live at the cost of using artificial ventilation,' but people use wheelchairs if they have a disability in the legs, and some people even want to live by using someone else's heart." Just as pacemaker devices have become a common way of supporting the lives of patients with arrhythmia, artificial ventilation could be accepted as support for another of the primary mechanisms of life.

ALS patients have normal intelligence. Even with an artificial ventilator, [we] can live splendidly as human beings as long as nursing is sufficient 
and other people help [us] by being as if they were [our] hands or legs. [I] would not dare let [my] life go away easily. (Matsumoto, 1995: 49)

In the paragraph just quoted, the subject of the first sentence is 'ALS patients', and Matsumoto generalized by stating that ALS patients have normal intelligence. However, in the second sentence, there is no grammatical subject. Indeed, subjects are not always required in Japanese grammar. By not placing a subject, he included himself in the general population of ALS patients. In the last sentence, he omitted the subject again but raised his tone and reasserted his own will. He then referred to a specific situation:

Due to family circumstances, a friend of a certain patient had to give up living with an artificial ventilator. The friend got angry, saying, 'are there no rights for the family of a patient who is being deprived of life?' Indeed, I believe that no one has a right to deprive patients of their lives. If the family cannot support the patient's care, I believe that society should be responsible for that support but, in reality, hospitals overtly resist accepting ALS patients. I cannot help but get angry that the lives of patients are disregarded like this in Japan, which is the second-largest economic superpower in the world. (Matsumoto, 1995: 49)

Speaking about someone else's experience helped Matsumoto to make his standpoint relatively objective, as if he belonged to the majority who are unaffected by the disease. He insisted that patients should be supported by society if their families are unable to support them. At a general level, he was angry about disregarded lives. From the perspective of an ALS patient, however, he worried about being a burden:

But if [I] now come to the psychology of patients, my mind is driven by complex thoughts. If [I] can move neither hand nor legs, [I] lose the ability to talk or eat, and also, if [I] am connected to an artificial ventilator, [I] may become a human of no use. If [my] existence has no value and [I] live only to put burdens on [my] family by forcing them to nurse [me], it seems to me that [I] should die. This could be [my] consideration for [my] family. Mr. A, who did not go on artificial ventilation, may have thought like this and chose to die. (Matsumoto, 1995: 49-50) 
Here, by again omitting the subject, Matsumoto intended to look at himself as an ALS patient objectively. The only subject implicitly written in this paragraph was ' $\mathrm{I}$ ' in the first sentence. For the other sentences in the paragraph, any personal pronoun, such as one, they, or we, could be used instead of I as a subject. Murakami (2020) documented this kind of ambiguity in his interview with a professional caregiver in which the subject floated back and forth between client and caregiver. Such lexical features could be regarded as an articulation of intersubjectivity as understood by Nishida.

Matsumoto's reflections now bring us back to the almost $70 \%$ of ALS patients who, even in Japan, do not choose TIV. It is obvious that TIV may not be feasible where insufficient medical resources are available for ALS patients. However, in richer countries that can afford such care, an implicit utilitarian perspective may be at work to discourage TIV. This perspective becomes explicit, and looks inevitable, in ventilator triage protocols for pandemics and disasters, such as the recent COVID-19 pandemic (e.g. DPI, 2020; Feinstein et alii, 2020; Rosenblum, 2020). The problem of utilitarianism is reflected in Matsumoto's remarks on burden, the value of life, and individual desires: "But everything ends when I die. I want to live. I want to stay in this world." He reaches this conclusion after a long monologue that lacks a clear grammatical subject.

Next we provide translations from a booklet entitled Ikiru chikara (Power to Live; 2006, third edition 2007). Edited by eleven ALS patients from an initiative by JALSA, the booklet comprises thirty-two essays by ALS patients or family members. Only five essays are by women, none of which discusses artificial ventilation or deals with decision-making about TIV. At the time the booklet was published, the use of TIV had been increasing in Japan - from $13 \%$ in 1982 to $24 \%$ in 1996 and $35 \%$ in 2005 (Hayashi, 2007). The aim of the booklet was to collect and publicize patients' experiences - to report how they felt when their symptoms appeared, how they received the diagnosis, and what their life was like afterwards. It includes sixteen essays on decision-making about TIV, twelve of which refer to topics related to family members. The first 
narrative was written by a 66-year-old man on TIV who had a wife and three daughters.

[...] I was pressed to make a decision to take one of two options: die naturally or prolong my life with artificial ventilation. [...] at that time, I thought it would be reasonable to choose to die naturally considering the mental, physical, and economic burdens on my family. (Wada, 2007: 39-40)

The word 'naturally' as used here refers to the biomedical fact that a person with ALS deteriorates monotonically towards death as a natural course. From this perspective, life aided by an artificial ventilator is unnatural. But the patient's wife and daughters encouraged him to live and in the end he went on TIV, even though he had once believed he should die because of the burdens on his family. In the following quotation by another patient, however, the word 'naturally' is used differently. Prompted by a visiting nurse, the author, a 51-year-old widower with three school-age sons, visits an ALS patient on TIV who is cared for at home by his wife:

I was impressed by how the couple cared naturally without putting pressure on their shoulders, and at the same time, being home with an artificial ventilator appeared natural and eased my anxiety considerably about using artificial ventilation. My elder sister, who visited the house together [with me], said that she might be able to handle [the situation], which made me feel relieved. (Uchiyama, 2007: 52)

This testimony provides a good example of onozukara appearing in the 'place' of care. It is interesting to note how the author uses the term 'natural' or 'naturally'. The word is first employed to characterize the couple's way of caring and then to express their being at home with an artificial ventilator - as if there were no intentionally acting subjects, only things happening onozukara in the place, or basho where the couple reside with the technology. As Murakami (2020) asserts, to avoid fatal accidents it is crucial for ALS patients to live in an orderly environment that runs in a 'natural' way on the intersubjective grounds of a patient-caregiver relationship. The extremely integrated situation that can result illustrates the fact that TIV patients 
who have spouses show a greater acceptance of tracheostomy, survive longer, and have a better QOL (Chiò, 2010; Tagami, 2014).

The last quotation we provide from this booklet was written by a 57-year-old man who had a wife, a daughter and a three-year-old granddaughter:

[...] because I often happened to have breathing difficulty and tasted suffering, I could naturally receive tracheostomy, and I think that the time for the attachment of an artificial ventilator had come. I had been telling my family that I could not decide until the time came. However, I simply came to accept their appreciation, believing that it's a matter of course to go on TIV, and to think to amaeru [verb form of amae]. Or maybe it had been thought [like that by myself] from the beginning. (Wakaiki, 2007: 46)

Here again, 'naturally' qualifies the process of receiving TIV and is now coupled with the key notion of amae to designate a family process. Because the patient's family believed that the shift to TIV was natural (a matter of course), he could amaeru to their appreciation and receive tracheostomy naturally.

This booklet provides many examples of family members playing important roles in helping patients decide to accept TIV. As mentioned earlier, since women did not deal with this topic, the testimonies we have quoted reflect the 'middle-aged men model' (Kawaguchi, 2014), by which the patients take the care they receive from their wives or daughters for granted. While the gendered nature of care is a well-known phenomenon (see Kawaguchi, 2009, in the context of ALS in Japan), its connection to kinship, though long ignored, is now being investigated (e.g. Comasd'Argemir and Soronellas, 2019).

In contrast to the above testimonies, Kawaguchi (2020) presents the case of a woman with ALS who said she had rejected TIV because her family did not say "I want you to live." In Kawaguchi's experience as former president of JALSA, many patients who go on a ventilator are encouraged to do so by their families and end up being grateful for it. Women, however, are at a disadvantage because of their traditional role as caregivers. This situation is documented not only in Japan but also in 
other countries, e.g. Italy, which has a 1.69 male/female TIV ratio (Spataro et alii, 2012), and Norway and Sweden, where a decade ago two thirds of TIV users were men (Tollefsen et alii, 2010). Hashimoto Misao, the most famous female ALS patient in Japan because of her public presence and activities, was diagnosed at the age of 32 when she had a daughter in kindergarten. She was later instrumental in undermining the 'middleaged men model' and developing the 'sakura model', by which caregivers are trained by patients and their families, and a patient acts as the manager of their care station (Kawaguchi, 2009, 2014). The ALS/MND Support Center Sakura Kai promotes this model, which is spreading in Japan and other countries.

The task force of the European Federation of Neurological Societies (Andersen et alii, 2005, 2012) suggests that TIV should be adopted only after full discussion of its pros and cons with the patient and their caregivers. In contrast, Tateiwa (2004) argues that patients with ALS should not have to wait to hear the judgment of those around them but should decide whether to live depending on their own desires. Only when a patient no longer needs to consult, ask, or confirm whether they should live is their survival assured. Hashimoto spoke for the larger community of affected individuals when she said in an interview, "the place where ALS patients can live is a city that is friendly to all people, such as the sick, the elderly and the disabled" (Kawaguchi, 2014: 61-62). Such a city would include professionals who can care for them 24 hours a day, 365 days a year. In Japan, a grassroots patients' movement emerged in the 1970s whose advocacy culminated in the 2013 Comprehensive Support for Persons with Disabilities Act. Combined with the 'sakura model', this law comes close to realizing the ideal of full care for persons with ALS.

\section{Conclusions}

Patient narratives in Japan have been driven by a desire to share experiences and information, encourage other affected individuals, and suggest ways for better ALS care (e.g. Matsumoto, 1995; Sasaki, 2006). Many of those narratives have been assimilated into ALS care manuals for nurses and caregivers. In most of these, middle-aged male patients 
often get upset because of misunderstandings by caregivers, who are often their wives or other family members, and try to correct them by typing messages for hours and hours. Doi's analysis of Japanese behavior through the concept of amae suggests it is as unrealistic to close one's eyes completely to interpersonal separation as it is to be overwhelmed by it and isolate oneself in despair over the difficulties in establishing human relationships (Doi, 1971). The middle-aged male patients we have discussed here do not appear to be desperate, in fact, but to be motivated to achieve with their caregivers a fusion like they enjoyed in childhood with their mothers. Whether this psychoanalytically-inspired interpretation is correct or not, the ideal of the inseparable nature of the subject (patient) and the object (caregiver), which is in line with Nishida's view of intersubjectivity, the dialectics of I and Thou, and the non-relative other, seems to reside inherently between the two and to originate in amae, which makes affected individuals positive, patient and confident despite their profound immobility.

In this connection we can mention the case of Masaoka Shiki (18671902), a major figure in the development of modern Japanese literature. Although this author suffered from tuberculosis of the spine rather than ALS , he was bedridden for the last three years of his life and experienced a situation of dependency similar to that of almost completely paralyzed ALS patients. He continued working on his essay collection Byōshō rokushaku (Six-foot sickbed) until two days before his death at he age of 34. The collection opens with the sentence, "Six-foot sickbed, this is my world." He spoke of caregivers as follows:

If they think that the sick are annoyed by their noise, they should go out to the room next door to hide for a while. If they think that the sick seem to be lonely and want someone nearby, they should not leave them even for a moment and stay with them. Or they should go and find someone who will come and talk softly and pleasantly. [...] Nurses need to know first and foremost the nature of the sick and their habits, but ordinary nurses rarely do this. In many cases, mothers, wives, elder sisters, younger sisters, etc. within the family, who had known the condition of the tantrum of the sick before they got sick, would do better. But in 
fact, they are not as the sick want them to be, and so the sick get upset (Masaoka, 1984: ch. 69).

In Masaoka's days, the family system was still strong in Japan and care could be provided within the family. His observations and expectations about caregiving demonstrate that the amae of the sick toward caregivers was open and accepted. On one hand, they reflect practices that are still consistent with the much more recent testimonies cited above. Beyond the strongly gendered nature of Masaoka's commentaries, they reflect considerable continuity in ideals of care. On the other hand, as the 'middleaged men model' declines over time, some male ALS patients move out of their homes to live separately from their families (e.g. Fujimoto, 2017), or professional caregivers substitute for family members and take care of those who stay at home.

The narratives of patients with advanced ALS and LIS attest to the difficulties they experience in calling attention to their needs and how often they must persevere in order to have their needs addressed. Their perseverance does not stem from self-indulgence but from the usual conditions of care. Murakami (2011) analyzed care as a process of establishing an intersubjective unit made up of patient and caregivers. Kawaguchi (2009) reflects on the days when her mother thoroughly resisted everything her caregivers did for her, from placing her hands and feet to changing her clothes and diapers. The mother's unrelenting resistance, which made her a difficult patient, was part of her learning to be a heavily disabled person - but it was also the process by which she unwittingly guided her caregivers to "the place where the subjectivity of care resided" (Kawaguchi, 2009: 60).

We began with what has been described as the 'Japanese bias', i.e. the fact that a greater proportion of Japanese ALS patients accept TIV than patients in other countries and that those patients survive longer than those in countries with a similar rate of TIV acceptance. Although this phenomenon is obviously overdetermined, one explanation for it is the uniquely high level of material support that is provided by the Japanese social system. When making their choice, Japanese ALS patients are less tormented by the idea of becoming an unbearable burden on their 
families because they know their costs will be covered and they will receive around-the-clock care. These material factors, however, have not prevented change. In a comparison of Japanese and American ALS patient preferences in relation to TIV, Rabkin et al. (2014:190) found that, contrary to expectations based on earlier findings,

both U.S. and Japanese patients on 24-h NIV were less likely to want TIV, as were patients who knew another patient with TIV. Finally, patients who decided to have TIV or who were undecided, had higher levels of energy, greater wish to live, and more sense of control over ALS than patients who had decided against TIV or who were undecided.

Although it is difficult to identify determining factors with certainty, the authors suggest that neurologist preferences, caregiver attitudes and a lack of advance planning may influence the probability of TIV use. At the time the 'Japanese bias' was being identified, researchers compared the emphasis on autonomy and patient choice in the US with the more 'paternalistic' attitude of medical professionals in Japan, where decisions were left to physicians who are usually committed to a life-prolonging approach (Borasio et alii, 1998). The subsequent weakening of the 'Japanese bias' converges with the fact that TIV is generally discouraged in Western countries, where the issue of whether to propose TIV for patients with ALS is still a matter of debate. Whatever the case, the extent to which patients are really "free to decide" remains unresolved (Spataro and La Bella, 2012).

In a review of the literature on this issue combined with a study of practices in major Swiss and French ALS centers, Héritier Barras et al. (2013) reported that improved secretion management and the use of various interfaces enable NIV to be employed 24 hours a day for prolonged periods and avoid TIV in many cases. TIV, they note, "is frequently initiated in emergency situations with lack of prior informed consent" and seems to be associated with a lower QOL and a higher risk of institutionalization than NIV. They observe that current practice in Switzerland and France tends to discourage TIV in ALS. "Fear of a 'LIS,' the high burden placed on caregivers, and unmasking cognitive disorders occurring in the evolution of ALS" all play a role when TIV is considered. In conclusion, TIV is clearly 
a "second line option, to be considered only when NIV fails and when prolonged survival is the goal and specific request of the patient" (Héritier Barras et al., 2013). In view of the above, Vianello and Concas (2014) are justified in wondering whether globalization will eliminate the 'Japanese bias': since NIV was introduced for clinical use in Japan, the switch rate from NIV to TIV has gradually decreased there. For example, before 2000 TIV use was 100\% (since NIV was not clinically available); between 2000 and 2004 it was 67\%; between 2005 and 2009 it was $42 \%$; and between 2010 and 2015 it was $24 \%$ (Hirose et alii, 2018).

However, just as the globalization of initially Western discussions on TIV and guidelines on its use in ALS are appearing to threaten the 'Japanese bias', medical and technological advances in the West may be moving in the opposite direction. As Héritier Barras et al. (2013) point out, the reluctance in using TIV

is strongly related to the absence of immediate hope in terms of therapeutic interventions and to the absence of communication or modes of empowerment of the patients on their environment when advanced in their disease. New technical devices for communication support such as Brain Computer Interfaces may change this in a rather near future, by facilitating communication and simple everyday tasks (reading, choosing music, videos, etc.). This will strongly influence the beliefs and convictions of healthcare professionals. New therapeutic approaches may also change the prognosis and attitudes toward endstage ALS, although unfortunately not in a near future. Last but not least, an integrated system of home care with specific training of providers, in order to alleviate the burden on caregivers, may change the focus of the discussion.

Some of the factors they mention as possibly changing prevalent practices may help bring about an experiential world of care that corresponds to that of the Japanese patients whose testimonies we have presented. This paradoxical situation underlines the potential value of the Japanese concepts we have explored not only for examining at least some of the cultural constituents of the 'Japanese bias', as we have done, but also for thinking more generally about the ideal conditions of care. 
In this paper we have explored the possible link between the 'Japanese bias' and philosophical developments in Japan. Three important philosophical concepts (basho, onozukara and amae) and related practices may shed light on the care situation of Japanese ALS patients, which is materially enabled by the resources of the country's health system. The basho of care is the 'place' or specific situation where the borders between self and other, subject and object, and subjective experience and objective reality are blurred. This place breaks down the absolute separation between the paralyzed individual and the staff that surround and support him or her. All live within the basho of onozukara, in a relational dynamics of care sustained by amae. Given appropriate material circumstances, long-term care emerges onozukara as an organic process in which each element interacts and unites with the others. The best long-term care can therefore be interpreted not purely in the light of its results, which are of course essential, but as a 'way'. Kadō, the way of flowers, is especially appropriate as a paradigm of this ideal since it aims to convey the state of onozukara itself. This does not consist of 'doing' but of 'being', as an experiential process that dissolves the distinctions between subject and object, self and other. ${ }^{33}$

\section{References}

Albert, S. M. and Wicks, P. (2019). "Rethinking the locked-in state for people with ALS". Neurology, 93, 419-420.

Andersen, P. M. et alii (2005). "EFNS task force on management of amyotrophic lateral sclerosis: guidelines for diagnosing and clinical care of patients and relatives". European Journal of Neurology, 12(12), 921938.

\footnotetext{
3 This article was prepared as part of the project Anthropology and Phenomenology of the Locked-in Syndrome (http://www.antropologia.urv.cat/en/research/projects/locked-in-syndrome/), Medical Anthropology Research Center, DAFITS, Rovira i Virgili University (URV), which receives support from URV (Ref. 7200109) and the Spanish Ministry of Science and Innovation (Ref. PID2019106723GB-I00). Dr. Himeno thanks Ritsumeikan University for enabling a six-month stay at DAFITS; Professors T. Mima and S. Tateiwa of Ritsumeikan University and Dr. K. Ishijima of Teikyo University for their insightful suggestions; and staff and colleagues at DAFITS for being their inspiration and friendly hospitality. We are also grateful to Professors Gereon Kopf and Rein Raud for their helpful commentaries on the first draft of this article.
} 
Andersen, P. M.etalii (2012). "EFNS guidelines on the clinical management of amyotrophic lateral sclerosis (MALS) - revised report of an EFNS task force". European Journal of Neurology. 19(3), 360-375.

Arisaka, Y. (2001). "The Ontological Co-Emergence of 'Self and Other' in Japanese Philosophy". Journal of Consciousness Studies, 8(5-7), 197-208. Borasio, G. D. et alii (1998). "Mechanical ventilation in amyotrophic lateral sclerosis: a cross-cultural perspective". Journal of Neurology, 245 (Suppl 2), S7-12.

Bouso, R. (2018). "De geidō a geijutsu. O caminho da arte e a arte como caminho na Escola de Kioto". Modernos \& Contemporâneos, 2(3), 2-12.

Clarke, J.J. (1997). Oriental Enlightenment: The Encounter Between Asian and Western Thought. London: Routledge.

Caudil, W. and Weinstein, H. (1969). "Maternal care and infant behavior in Japan and America". Psychiatry, 32 (1), 12-43.

CHiò, A. et alii (2010). "Tracheostomy in amyotrophic lateral sclerosis: a 10year population-based study in Italy". Journal of Neurology, Neurosurgery, and Psychiatry, 81, 1141e1143.

Christodoulo, C. et alii (2015). "Opinions of Japanese and American ALS caregivers regarding tracheostomy with invasive ventilation (TIV)". Amyotrophic Lateral Sclerosis and Frontotemporal Degeneration, 17, 47-54.

Comas-d'Argemir, D. and Soronellas, M. (2019). "Men as carers in longterm caring: doing gender and doing kinship". Journal of Family Issues, 40(3), 315-339.

Davis, B. W. (2019). "The Kyoto School”. In The Stanford Encyclopedia of Philosophy. <https://plato.stanford.edu/archives/sum2019/entries/ kyoto-school/>.

DoI, T. (1971). Amae no kōzō [The Anatomy of Dependence]. Tokyo: Kōbundō. DPI (2020). Japan National Assembly of Disabled Peoples' International (DPI-Japan), and other organizations. "Request for the guarantee of human rights for persons with disabilities in response to COVID-19." Letter to Shinzo Abe, Prime Minister of Japan. http://dpi-japan.org/ en/2020/04/13/request-for-the-guarantee-of-human-rights-forpersons-with-disabilities-in-response-to-covid-19/. 
Dreyer, P. et alii (2014). "Survival in ALS with home mechanical ventilation non-invasively and invasively:A15-year cohort study in west Denmark". Amyotrophic Lateral Sclerosis and Frontotemporal Degeneration, 15, 62-67.

Ето, J. (1978). Seijuku to sōshitsu [Maturity and Loss]. Tokyo: Kōdansha.

Feinstein, M. M. et alii. (2020). "Considerations for ventilator triage during the COVID-19 pandemic". The Lancet Respiratory Medicine, DOI: 10.1016/S2213-2600(20)30192-2.

Fuıмото, K. (2017). Tojikomerareta boku [Trapped]. Tokyo: Chuōkōron Shinsha.

Hamanaka, M. (2007). "Yori ningen rashiku ikiru tame ni [In order to live humanly]”. In SASAKI, K. et alii (eds.). Ikiru Chikara [Power to live]. Tokyo: Iwanami Shoten. 55-57.

HAYASHI, H. (2007). "'Atarashii ALS kan' ni tatte [From the perspective of 'new concept of ALS']" In SASAKI, K. et alii (eds.). Ikiru chikara [Power to live] (pp. 133-135). Tokyo: Iwanami Shoten.

Heidegger, M.; Hisamatsu, S. et alii (2017). "Art and Thinking: Protocol of a Colloquium on May 18, 1958". Trans. C. Culbertson and T. Keiling. Philosophy Today, 61(1), 47-51.

Heisig, J. W.; Kasulis, T. P. and Maraldo, J. C. (eds.) (2011). Japanese Philosophy: A Sourcebook. Honolulu: University of Hawai'i Press.

Héritier Barras, A. C. et alii (2013). "Is tracheostomy still an option in amyotrophic lateral sclerosis? Reflections of a multidisciplinary workgroup". Swiss Medical Weekly, 143, w13830, DOI: 10.4414/ smw.2013.13830.

Hirano, Y. and Yamazaki, Y. (2010). "Ethical issues in invasive mechanical ventilation for amyotrophic lateral sclerosis". Nursing Ethics, 17 (1). 5163.

Hirose, T. et alii (2018). "Clinical characteristics of long-term survival with noninvasive ventilation and factors affecting the transition to invasive ventilation in amyotrophic lateral sclerosis". Muscle \&Nerve, 58(6), 770776.

IKENOBō, S. (1970) [1542]. Ikenobō sen'ō kuden [Oral Instructions by Ikenobō Sen'ō]. In Kadō kosho shūsei [Collection of Old Kadō Books]. Kyoto: Shibunkaku. 
IRIE, G. (1970). Ikebana chisuji no fumoto [Ikebana Bottom of Thousand Streams] In Kadō kosho shūsei [Collection of Old Kadō Books]. Kyoto: Shibunkaku. Jansen, M. B. (2000). The Making of Modern Japan. Cambridge, MA: Harvard University Press.

Kasulis, T. P. (2018). Engaging Japanese Philosophy: A Short History. Honolulu: University of Hawai'i Press.

KaWAI, H. (1997). Bosei shakai nihon no byōri [Pathology of Japanese Maternal Society]. Tokyo: Kōdansha.

KaWAgUCHI, Y. (2009). Ikanai shintai [The Body Still Breathing]. Tokyo: Igaku Shoin.

KaWAGUCHI, Y. (2012). ALS no jinkkō kokyū ryōhō wo meguru kattō - ALS/MND kokusai dōmei, nihon ALS kyōkai no dōkō wo chüshin ni [Conflicts Over the Treatment Using Artificial Ventilation in ALS - Focusing on Trends of the International Alliance of ALS/MND Associations and Japan ALS Association], Doctoral thesis, Ritsumeikan University.

Kawaguchi, Y. (2014). Matsugo wo koete [Beyond Terminal]. Tokyo: Seidosha. KaWAGUCHI, Y. (2020). "Impact of the Japanese disability homecare system on ALS patients' decision to receive tracheostomy with invasive ventilation". Neuroethics, 13(2), 181-191.

KimurA, F. (2016). "Kin ishukusei sokusaku kōka shō - Jinkō kokyūki sōchaku no haikei inshi to yogo bunseki" ["ALS - background factors for the attachment of artificial ventilator and analysis of prognosis"]. Rinshō shinkeigaku [Clinical Neurology], 56, 241-247.

Kopf, G. (1999). "Alterity and nothingness: an exploration of Nishida's I and Thou". Arc: Journal of the Faculty of Religious Studies at McGill University, 27, 109-122.

Kopf, G. (2003). "On the Brink of Postmodernity: Recent JapaneseLanguage Publications on the Philosophy of Nishida Kitarō". Japanese Journal of Religious Studies, 30(1-2), 133-156.

Krueger, J. W. (2008). "Nishida, Agency, and the 'Self-Contradictory' Body". Asian Philosophy, 18(3), 213-229.

Krummel, J. W. M. (2012). "Basho, world, and dialectics: an introduction to the philosophy of Nishida Kitarō". In Place and Dialectic: Two Essays 
by Nishida Kitarō. New York: Oxford University Press, DOI: 10.1093/ acprof:oso/9780199841172.001.0001.

Krummel, J. W. M. (2018). "The Kyoto School Philosophy on Place: Nishida and Ueda". In E. Champion (ed.), The Phenomenology of Real and Virtual Places, 94-122. London: Routledge.

Kurasawa, Y. (1987). Geidō no Tetsugaku [The Philosophy of Geidō]. Osaka: Tōhō shuppan.

Kuzma-Kozakiewicz, M. et alii (2019). "An observational study on quality of life and preferences to sustain life in locked-in state". Neurology, 93, e938-e945.

Maraldo, J. C. (2019). "Nishida Kitarō". In The Stanford Encyclopedia of Philosophy, <https://plato.stanford.edu/archives/win2019/entries/ nishida-kitaro/>.

Markus, H. R. and Kitayama, S. (1991). "Culture and the self: implications for cognition, emotion, and motivation”. Psychological Review, 98 (2), 224-253.

Masaoka, S. (1984). Byōshō rokushaku [Six-foot sickbed]. Tokyo: Iwanami Shoten.

Matsumoto, S. (1995). Akusai to no tatakai [Fight with a Bad Wife]. Tokyo: Seizansha.

Miller, R. G., et alii (1999). "Practice parameter: the care of the patient with amyotrophic lateral sclerosis (an evidence-based review): report of the Quality Standards Subcommittee of the American Academy of Neurology: ALS Practice Parameters Task Force". Neurology, 52 (7). 1311-1323.

Miller, R. G., et alii (2009). "Practice parameter update: the care of the patient with amyotrophic lateral sclerosis: multidisciplinary care, symptom management, and cognitive/behavioral impairment (an evidence-based review): report of the Quality Standards Subcommittee of the American Academy of Neurology" Neurology, 73 (15): 1218-26.

Murakami, Y. (2011). Kizu to saisei no genshōgaku [Phenomenology of Injury and Regeneration]. Tokyo: Seidosha. 
Murakami, Y. (2020). "Phenomenological analysis of a Japanese professional caregiver specialized in patients with amyotrophic lateral sclerosis" Neuroethics, 13(2), 239-247.

NAKANE, C. (1970). Tate shakai no ningen kankei tan'itsu shakai no riron [Human Relations in a Vertical Society: The Theory of Homogeneous Society]. Tokyo: Kōdansha.

Nishida, K. (1949). Nishida kitarō zensyū [Collected Works by Nishida Kitarō] (4). Tokyo: Iwanami Shoten.

Nishida, K. (1950). Nishida kitarō zensyū [Collected Works by Nishida Kitarō] (12). Tokyo: Iwanami Shoten.

Nishida, K. (1996). Zen no Kenkyū [A Study of Good]. Tokyo: Iwanami Shoten.

OZAWA-DE SILVA, C. (2002). "Beyond the body/mind? Japanese contemporary thinkers on alternative sociologies of the body". Body and Society, 8(2), 21-38.

OzaWa-de Silva, C. (2006). Psychotherapy and Religion in Japan: The Japanese Introspection Practice of Naikan. New York: Routledge.

Phillips, J. (2001). "Kimura Bin on Schizophrenia". Philosophy, Psychiatry, \& Psychology, 8(4), 343-346.

RABkin, J. et alii (2014). "Japanese and American ALS patient preferences regarding TIV (tracheostomy with invasive ventilation): A crossnational survey". Amyotrophic Lateral Sclerosis and Frontotemporal Degeneration, 15(3-4), 185-191.

Raud, R. (2014). "What is Japanese about Japanese Philosophy?" In J. LiU and M. SANo (eds.). Rethinking "Japanese Studies" from Practices in the Nordic Region (15-27). Kyoto: International Research Center for Japanese Studies.

Rosenblum, L. (2020). "Facing Covid-19 in Italy - ethics, logistics, and therapeutics on the epidemic's Front Line." The New England Journal of Medicine, DOI: 10.1056/NEJMp2005492.

RousSEAU, M. C. et alii (2011). "Quality of life of ALS and LIS patients with and without invasive mechanical ventilation". Journal of Neurology, 258, 1801-1804. 
SANCHO, J. et alii (2011). "Home tracheotomy mechanical ventilation in patients with amyotrophic lateral sclerosis: causes, complications and 1-year survival". Thorax, 66(11), 948-952.

SASAKI, K. (2006). Yasashisa no rensa [A Chain of Affection]. Tokyo: Hitonaru Shobō.

Shimizu, M., Park, H. and Greenfield, P. (2014). "Infant sleeping arrangements and cultural values among contemporary Japanese mothers". Frontiers in Psychology, 5, art. 718, DOI: 0.3389/ fpsyg.2014.00718.

Spataro, R., et alii (2012). "Tracheostomy mechanical ventilation in patients with amyotrophic lateral sclerosis: clinical features and survival analysis". Journal of the Neurological Sciences, 323, 66-70.

Spataro, R. and La Bella, V. (2012). "Ethical issues: invasive ventilation in amyotrophic lateral sclerosis". British Medical Journal Supportive and Palliative Care, 2, 85-86.

Sugimoto, Y. (1999). "Making sense of nihonjinron". Thesis Eleven, 57, 81-96. TAGAmi, M. et alii (2014). "Tracheostomy and invasive ventilation in Japanese ALS patients: Decision-making and survival analysis: 19902010". Journal of the Neurological Sciences, 344, 158-164.

TATEIWA, S. (2004). ALS fudō no shintai to iki suru kikai [ALS Immovable Body and Breathing Machine]. Tokyo: Igaku Shoin.

Tollefsen, E. et alii (2010). "Amyotrophic lateral sclerosis: gender differences in the use of mechanical ventilation". European Journal of Neurology, 17(11), 1352-1357.

Uchiуama, I. (2007). "Kaigo ryoku wo kangaeru" ["Consideration on care power"]. In SASAKI, K. et alii (eds.). Ikiru chikara [Power to Live] (pp. 4854). Tokyo: Iwanami Shoten.

Vianello, A. and Concas, A. (2014). "Tracheostomy ventilation in ALS: A Japanese bias". Journal of the Neurological Sciences, 344(1-2), 3-4.

WADA, M. (2007). "ALS kuranke no hiki komogomo" ["Joy and sorrow of an ALS patient"]. In SASAKI, K. et alii (eds.). Ikiru chikara [Power to Live] (pp. 38-41). Tokyo: Iwanami Shoten. 
WaKaiki, Y. (2007). "Kyō made wo furikaette" ["Retrospection to date"] In SASAKI, K. et alii (eds.). Ikiru chikara [Power to Live] (pp. 44-47). Tokyo: Iwanami Shoten.

Watsui, T. (2016) [1935]. Nihongo to tetsugaku no mondai [The Problem of Japanese Language and Philosophy]. Okazaki: Keibunkan Shoten. 